\title{
A Avaliação Psicossocial no Contexto da Adoção: Vivências das Famílias Adotantes ${ }^{1}$
}

\author{
Liana Fortunato Costa ${ }^{2}$ \\ Universidade Católica de Brasília e Universidade de Brasília \\ Niva Maria Vasques Campos \\ Serviço Psicossocial Forense do Tribunal de Justiça do Distrito Federal e Territórios
}

\begin{abstract}
RESUMO - Foi realizada uma pesquisa de enfoque qualitativo com duas famílias adotantes, através de entrevista de grupo focal em um serviço de adoção de uma Vara da Infância e da Juventude. De acordo com os participantes, são aspectos essenciais do atendimento: o modo de avaliação; a verdade sobre a filiação ser dita à criança adotada; a vivência de família do casal; a experiência do estudo psicossocial durante o processo de adoção; a necessidade de informação e campanhas de divulgação; o papel do acaso e do divino no acerto da escolha da criança selecionada e a confiança no trabalho técnico. Foi possível concluir que o contexto judiciário pode ser um importante catalisador para a mudança, mas pode também ser precursor de arbitrariedades, especialmente no Brasil, em que ainda se fazem sentir a desigualdade e a falta de cidadania. Em suma, é fundamental entender o judiciário como um contexto de possibilidades, ao invés de um contexto de limites.
\end{abstract}

Palavras-chave: adoção; famílias adotantes; contexto judicial; avaliação psicossocial.

\section{Psychosocial Evaluation of Adoption: The Perspective of the Adopting Families}

\begin{abstract}
A qualitative research was developed with two adopting families, based on focal group interview conducted by the Adoption Service of a Childhood and Adolescence Law Court. According to the participants, the main aspects of the psychosocial study are: the way that families are evaluated; the importance of telling the truth to the adopted child; undergoing the psychosocial study during the process of adoption; the necessity of informative campaigns; the role of chance and of the divine in correctly chosing the child; and the trust in the technical work. The data indicated that the judiciary context can be an important catalyst of change, but it can also be the forerumer of arbitrary decisions, specially in Brazil, where inequality and lack of citizenship are still exist. Essentially, it's fundamental to understand the judiciary context not as a context of limits, but as a context of possibilities.
\end{abstract}

Key words: adoption; adopting families; judiciary context; psychosocial evaluation.

O texto aqui apresentado está baseado numa pesquisa realizada num Setor Psicossocial de uma Vara da Infância e Juventude (VIJ), com os técnicos responsáveis pelos estudos psicossociais e as famílias que já adotaram uma criança seguindo os trâmites legais para adoção. Embora a pesquisa tenha contemplado essas duas dimensões complementares, por impossibilidade de poder apresentá-la na íntegra, vamos nos ater aos procedimentos que enfocam apenas as famílias, por considerarmos que é muito pouco conhecido o universo das famílias que adotaram crianças através de ações plenamente legais.

A pesquisa original teve como tema a concepção de família idealizada no processo de adoção. Seus objetivos foram: conhecer se existe, no processo de adoção, uma concepção de família idealizada, na perspectiva dos técnicos e também na perspectiva das famílias que se apresentam ao Juizado querendo adotar uma criança; e que outras dimensões estão presentes no discurso quando esses sujeitos, técnicos e famílias, dialogam sobre o tema. Pretendemos, portanto, enfocar a experiência dessas famílias durante o processo de adoção,

1 Esse artigo foi baseado na dissertação de mestrado intitulada "A família nos estudos psicossociais de adoção: uma experiência na Vara da Infância e da Juventude do Distrito Federal", defendida na Universidade de Brasília, realizada pela segunda autora sob a orientação da primeira.

2 Endereço: SQN 104 Bloco D ap. 307. 70733-040 Brasília, DF, Brasil.

E-mail: lianaf@zaz.com.br principalmente nas relações estabelecidas com o contexto jurídico - como um contexto avaliador e normativo - através do estudo psicossocial que indica positivamente ou não a adoção.

Nesse projeto, manifestamos o desejo de encarnar a metáfora, proposta por Kvale (1996), do "pesquisador como um viajante". Aquele que empreende uma jornada através de uma terra desconhecida, com ou sem mapas. Aquele que conversa com as pessoas, que ouve as histórias do mundo vivido por elas, que deliberadamente procura lugares ou tópicos específicos. Aquele que descreve qualitativamente tudo que vê e ouve e reconstrói em histórias que poderão ser contadas e recontadas. Aquele cuja jornada não proporciona somente um novo conhecimento, mas um processo de reflexão e, principalmente, uma mudança no viajante.

\section{Crianças Abandonadas e Famílias Adotantes: Alguns Aspectos Teóricos}

Consultando os dados estatísticos sobre as famílias adotantes no Distrito Federal, nos anos de 1998 e 1999, verifica-se que predominaram a adoção de crianças por casais $(81 \%)$, e por pessoas que não estavam inscritas previamente para adoção (em torno de $80 \%$ ). Os dados sócio-demográficos dos adotantes não mostraram diferença significativa em relação ao perfil da população do DF, quando comparados 
aos fornecidos pela CODEPLAN (1998; 1999): a maioria é natural do Nordeste e Centro-Oeste, residente em Taguatinga e Ceilândia. O tempo de convivência marital teve uma distribuição relativamente equilibrada nas faixas acima dos quatro anos de convivência, com maiores concentrações nas faixas de 11 a 15 anos e acima de 20 anos.

Entre os casais, pouco mais da metade possuía filhos biológicos em comum, dado que se contrapõe ao senso comum, que aponta a impossibilidade de gerar filhos biológicos como uma das principais motivações para adoção. Este dado correlacionado ao tempo de convivência marital mais freqüente (de 11 a 15 anos e acima de 20 anos) pode indicar que o momento no ciclo de vida da família pode influenciar na decisão pela adoção, possibilitando uma disponibilidade maior para tal em famílias cujos filhos estejam na fase da adolescência ou início da vida adulta. Entre os principais motivos para adoção que foram registrados em 1998, o "desejo de exercer a maternidade/paternidade" ficou em primeiro lugar, seguido de: “ajuda ao próximo". Em 1999, o primeiro motivo indicado se manteve em primeiro lugar, seguido de "projeto de adotar". O motivo "ajuda ao próximo" ficou em terceiro lugar. Essas informações dizem respeito ao preenchimento de questionários internos do Setor de Adoção no qual a pesquisa se passou. O perfil dos pais adotivos de pesquisa realizada por Weber (1998) revelou que $91 \%$ dos pais adotivos eram casados, com idade até 40 anos e $55 \%$ não possuíam filhos biológicos. A motivação principal para adoção foi o desejo de ter filhos. Outras motivações evidenciadas foram: necessidade de preencher a solidão; proporcionar companhia a um filho único; escolher o sexo do próximo filho; substituir um filho natural falecido, entre outras. Segundo a referida pesquisa, a maioria dos pais adotivos das classes sociais mais elevadas adotou através dos Juizados da Infância e da Juventude, enquanto a maioria dos pais adotivos com nível econômico menos privilegiado realizou adoções ilegais (registrar uma criança em seu próprio nome sem passar pelos trâmites legais). Por outro lado, estes últimos mostraram-se menos exigentes em relação à criança, adotando crianças maiores, negras ou que simplesmente que estavam por perto precisando de ajuda.

Quando estudamos a temática da adoção é inevitável reportarmo-nos à questão do abandono. Segundo Vargas (1998):

\section{O abandono legal não está definido claramente no Estatuto da Criança e do Adolescente-permite respeitar o desejo dos pais de não assumir o filho (agilizando o processo), oferecendo, ao mesmo tempo, possibilidade à criança de ter a segunda melhor chance de construir relações estáveis que são vitais para o seu desenvolvimento (p.17).}

Contudo, para a autora, este desejo dos pais de não assumir o filho precisa ser questionado em um país onde a maior parte da população se encontra abandonada pelo Estado, sem condições de saúde, moradia e educação. Neste sentido, até que ponto existiria liberdade nesta escolha de entregar ou abandonar um filho? Até que ponto isto seria realmente uma escolha dos pais? Concordamos com essa autora no tocante à relação entre adoção e abandono. Entretanto, existem diversos aspectos de abandono nesta relação.

O que a autora citada define como "abandono legal" é o consentimento necessário que os genitores ou representantes legais do adotando precisam dar para que ocorra a adoção, considerando esse aspecto como uma possibilidade. Em muitos casos, a entrega de uma criança em adoção não pode ser vista necessariamente como "abandono", mas como um ato - e pode-se pensar, em um certo sentido, responsável - de pais que não estão disponíveis para assumir sua prole, abrindo mão de seu direito sobre a criança/adolescente e que, a partir deste ato, propiciam uma outra chance para a criança estabelecer relações afetivas estáveis e saudáveis para seu desenvolvimento. Com relação a essa questão da definição de abandono, Motta (2001) nos chama atenção para a reflexão necessária sobre a sua utilização, propondo a substituição por termos menos carregados de preconceitos, como entrega. Talvez a palavra entrega expresse melhor os dramas e conflitos que as mães vivem ao entregarem seus filhos para adoção.

O termo disponibilidade é também utilizado por Berthoud (1998) para se referir à paternidade possível, como a disponibilidade emocional e afetiva de um homem ou mulher em determinado momento da vida para assumir a função parental. Entregar e abandonar são experiências diferentes, embora a prática no cotidiano de uma VIJ mostre que ambas dimensões coexistem, muitas vezes, em condições diversas e freqüentemente adversas. Por outro lado, muitas vezes, a doação ou entrega de um filho tem um aspecto diferente. Ainda que a genitora entregue a criança por sua própria conta (sem a mediação da autoridade judiciária), muitas vezes, existiu o reconhecimento de sua não disponibilidade para a maternidade/paternidade e uma preocupação e investimento sobre esta criança no sentido de protegê-la e confiá-la a outrem. Entretanto a condição de abandono vivida pelos genitores (em especial pela genitora) parece ter uma dimensão importante e ser um fator preponderante para a entrega de uma criança e, possivelmente, também para seu conseqüente abandono. Embora não se possa generalizar, já que outros fatores parecem estar atuando conjuntamente, e ainda, nos casos de crianças encontradas em via pública - na maioria das vezes, desconhece-se por completo sua origem e os motivos pelos quais foram abandonadas - as condições de exclusão e abandono de grande contingente de nossa população parecem fatores importantes na entrega e abandono de crianças.

Como Venâncio (1999) ressalta, as normas, leis e práticas assistenciais no Brasil, que estigmatizam o pobre, imputando-lhes

irresponsabilidade e desamor em relação à prole, deram origem a uma perversidade institucional que sobrevive até nossos dias: paradoxalmente, desde os séculos XVIII e XIX, a única forma de as famílias pobres conseguirem apoio público para a criação de seus filhos era abandonando-os (p.13).

A condição de abandono e exclusão da genitora pode ser facilmente identificada a partir dos dados estatísticos levantados pela VIJ/DF, relativos aos processos de adoção dos anos de 1998 e 1999. A maioria das genitoras é jovem (até 30 anos), solteira, pobre, com baixa escolaridade e pouca qualificação profissional (a maioria é doméstica), procedente de regiões pobres do país - principalmente do Nordeste (Ghesti, Campos \& Silveira, 2000). Verificamos que essas informações coincidem com o perfil da mãe doa- 
dora encontrado por Weber (1999) a partir de levantamento estatístico de processos de adoção do Juizado da Infância e da Juventude de Curitiba-PR. Esse trabalho mostrou que a maioria das mães doadoras é jovem (idade entre 15 e 20 anos) e solteira; entre os principais motivos para a colocação da criança para adoção destacam-se: a falta de recursos materiais ( $1^{\circ}$ lugar) e a rejeição da criança pela mãe $\left(2^{\circ}\right.$ lugar $)$. Tais dados são comparáveis, também, com os resultados de pesquisa realizada por Giberti, De Gore e Taborda (1997), na Argentina, onde essas mães, definidas pelas autoras como excluídas, são na sua maioria jovens, solteiras, pobres, com baixa escolaridade e sem qualificação profissional.

Muitas vezes, a alegação de dificuldades financeiras e materiais, por parte das genitoras que entregam a criança para adoção, parece ser mais fácil de aceitação e com um menor custo de sanção social. O curioso é que a própria sociedade que julga severamente a mãe que entrega ou abandona um filho, não se envergonha do fato desta mãe alegar agir assim em função da desigualdade social, da pobreza e/ou de seu próprio abandono. Tampouco julga com a mesma severidade o pai que, na maioria das vezes, segundo relato de muitas genitoras atendidas no Setor de Adoção, soube da gravidez e optou por não assumir sua prole.

Essas observações coincidem também com a citada pesquisa de Weber (1999) que identificou que, de modo geral, as solteiras contaram “... ao pai biológico sobre a gravidez e este decidiu por não assumir a paternidade.... este foi um dos fatores que colaboraram para que a mãe biológica decidisse por entregar a criança em adoção" (p.143).

O tema é complexo e com múltiplas vertentes e interpretações. A genitora pode alegar o problema socioeconômico para não revelar sua rejeição pela criança, em função das representações sociais atuais acerca da maternidade, que ainda mistificam e naturalizam o amor materno como mostra Badinter (1980/1985). Por sua vez, esta rejeição pode estar menos relacionada à falta de recursos financeiros, e mais associada à falta de apoio do pai da criança e/ou familiares, ou ainda da sociedade em geral. Por outro lado, do ponto de vista psicológico, precisamos ter em mente que, como essa autora ressalta, "o instinto materno é um mito", não se encontra "nenhuma conduta universal e necessária da mãe" (p. 367). Desta forma, a entrega de uma criança em adoção não poderia ser uma solução eticamente desejável para uma gravidez inoportuna? Se o sentimento de afeto pela criança está ameaçado pelas contingências, não seria melhor abrir mão do filho e entregá-lo para alguém capaz de amá-lo? E essa entrega, não poderia ser considerada como um ato responsável e consciente em defesa da vida, ao invés de prova de miséria, maldade e loucura?

Assim como no trabalho apresentado por Weber (1999), no tocante às genitoras, outro dado que chama atenção no levantamento estatístico da adoção no DF, é o forte peso da categoria "desconhecido" em todas as variáveis estudadas. Além de diferenças culturais em relação à vivência parental para cada gênero, a própria ênfase na coleta de informação sobre as genitoras pode revelar um viés dos trabalhadores da área que priorizam obter mais informações sobre as genitoras do que sobre os genitores. Contudo, já que muitas declaram desconhecer o paradeiro dos parceiros, isso poderia ser inviável.
Mas, o grande desconhecimento da realidade dos genitores e genitoras não pode ser atribuído única e exclusivamente ao desconhecimento de seu paradeiro. Esse desconhecimento pode também estar associado a uma falta de cuidado com a coleta e preservação das informações e, até mesmo, a sua sonegação por parte dos envolvidos (adotantes, genitora, intermediários). Ghesti e cols. (2000) interpretaram que esse desconhecimento significa, por vezes, um desejo dos adotantes de apagar a existência das genitoras, ou ainda, excluí-las mais uma vez. Na verdade, essa atitude pode revelar um desejo de apagar a história da criança, sua origem inferior ou vergonhosa.

Imber-Black (1993/1994) alerta para que estejamos atentos ao significado daquilo que é mantido secreto - para a autora, os segredos são fenômenos sistêmicos e a adoção, muitas vezes, carrega consigo estigma, vergonha e dor. Tais sentimentos poderiam estar relacionados à infertilidade dos adotantes, ilegitimidade do adotando, conduta sexual da genitora socialmente considerada reprovável.

Um outro fator que pode também estar relacionado ao desconhecimento da realidade dos genitores e ao desejo de apagar a história pregressa da criança é a negação da adoção enquanto uma forma diferente de exercício da paternidade/ maternidade. Hartman (1993/1994) afirma que a adoção desenvolveu-se apoiada na negação da diferença entre a parentalidade adotiva e a biológica.

Para concebermos a adoção desta maneira, e para apoiarmos esta negação, qualquer coisa que a torne diferente deve ser negada ou minimizada. A maior ameaça à negação da diferença é a existência da família biológica e, portanto, esta conexão deve ser total e permanentemente rompida (Hartman, 1993/1994, p. 95).

No Brasil, pela lei, mesmo nos casos em que a adoção foi realizada a partir de um acordo anterior entre genitores e adotantes, juridicamente os primeiros perdem todos os direitos sobre o filho, inclusive o de visitas. Na prática, encontramos muitas mulheres gerando filhos, ano após ano, que não podem criar. Ainda assim, pouco se sabe sobre as repercussões que a entrega de um filho acarreta em suas vidas. As mães - e por que não, também os pais? - que abandonam e aquelas que entregam seus filhos para adoção, configuram-se fontes importantes de pesquisa, especialmente em países como o nosso, fornecedor de crianças para a adoção.

É preciso ressaltar que o desconhecimento e, especialmente, os segredos com relação à história de origem da criança adotável/adotada poderão trazer dificuldades para as mesmas e para as famílias adotantes. Sentimentos de vazio experienciados por muitos adotados, dificuldades na comunicação e nas relações interpessoais, muitas vezes são conseqüências danosas decorrentes dos segredos e não-ditos sobre sua origem e adoção. Por outro lado, torna-se de fundamental importância que os trabalhadores do Poder Judiciário procurem obter e manter todas as informações pertinentes à origem e história de vida do adotando/adotado a fim de que este possa reconstruir sua história, facilitando a construção de uma auto-imagem clara e definida.

Nabinger (2000) ressalta a importância do tema e apresenta a experiência da Vara da Infância e Juventude do Rio 
Grande do Sul na confecção de uma pasta para cada criança contendo informações, fotos, desenhos, cartas e outros documentos. Tal pasta poderia se constituir em um documento oficial sobre a criança com relatórios de acompanhamento, fotos do seu desenvolvimento, configurando-se uma importante fonte de pesquisa que pudesse facilitar e enriquecer o levantamento de dados sobre sua vida.

\section{Existe uma família idealizada na adoção?}

Casellato (1998) afirma que, no Brasil, a demanda para adoção ainda se caracteriza pela adoção clássica, ou seja, buscar a solução de conflitos ou a satisfação das necessidades do adotante e não exatamente do adotado. No contexto onde essa pesquisa se passou, do ponto de vista psicossocial, no processo de inscrição, percebe-se que a busca por adoções clássicas ainda predomina, tendo em vista a maior procura por crianças claras, semelhantes fisicamente aos adotantes, recém-nascidas/bebês e saudáveis. Observa-se também, como no resto do país, uma maior procura por crianças do sexo feminino. As explicações para isto podem estar relacionadas aos estereótipos culturais de gênero que relacionam o sexo feminino à docilidade, beleza e domesticidade. Pode-se dizer também que, semelhante ao perfil nacional, à medida que a criança fica mais velha ou, ainda, quando a criança tem problemas de saúde ou é portadora de deficiência, suas chances para adoção diminuem bastante.

Até março de 2001, existiam quarenta e uma crianças cadastradas para adoção no DF. Destas, dez crianças têm até três anos de idade, 23 situam-se na faixa de quatro a onze anos e oito estão acima de doze anos. Vinte e sete são do sexo masculino e vinte e duas têm boa saúde. São consideradas de difícil colocação, as crianças mais velhas, não brancas e com problemas de saúde - pois não se encaixam no perfil predominantemente escolhido/desejado pelos adotantes. Pensamos que por trás da idealização da criança a ser adotada - um filho perfeito, sem problemas de saúde, semelhante fisicamente aos pais, recém-nascido, cujo comportamento acredita-se que poderá ser mais facilmente moldado pelos adotantes - pode estar o desejo de imitar ao máximo a situação biológica idealizada narcisicamente e/ou ainda encobrir os temores e receios com relação a história, origem e genética da criança.

Schettini (1998b) aponta para a supervalorização dos laços de sangue em nossa cultura. Ele alerta que, na nossa sociedade, "a ligação hereditária é um pressuposto indiscutível que dita as normas de valorização e continuidade familiar. Nesse contexto, a adoção é vista como algo espúrio, paralelo, inautêntico e artificial" (p. 29). São comuns questionamentos sobre a conveniência ou não de incluir uma pessoa estranha na condição de filho. Contudo, o autor aponta para o fato de que, no aspecto afetivo, as relações familiares não são garantidas pelos laços biológicos. Para ele, a família constituída dentro desses critérios de "amor obrigatório" e "amor espontâneo" apresentaria formas dinâmicas diferenciadas e, em ambas, o fator preponderante para o estabelecimento da relação de afeto seria a convivência. $\mathrm{O}$ autor alerta para o medo do desconhecido, da hereditariedade patológica da criança adotada que, muitas vezes, invadem os pais adotivos e afirma que "o medo das deficiências de- correntes do passado biológico do filho adotado não é em nada diferente da mesma possibilidade em relação aos filhos gerados biologicamente" (p. 33).

\section{Método}

A proposta metodológica norteadora dessa pesquisa foi a investigação qualitativa de González-Rey (1999), que se apóia em três princípios: (1) o conhecimento é uma produção construtiva-interpretativa; (2) o processo de produção do conhecimento tem um caráter interativo e (3) a significação da singularidade como nível legítimo da produção do conhecimento. A investigação qualitativa, fundamentada na epistemologia qualitativa, não é orientada para a produção de resultados finais que possam ser tomados como referentes universais e invariáveis sobre o estudado, e sim para a produção de novos momentos teóricos que se integrem organicamente ao processo geral de produção de conhecimentos.

$\mathrm{O}$ contexto da investigação foi a Vara da Infância e da Juventude. Vale explicar que todos os pedidos de adoção, por determinação judicial, são encaminhados para estudo psicossocial ao Setor de Adoção, que era composto, à época da pesquisa, de seis psicólogas e sete assistentes sociais. Essa determinação encontra respaldo no Estatuto da Criança e do Adolescente (art. $50 \S 1^{\circ}$ ) e visa proteger e garantir direitos fundamentais da criança e do adolescente. Num caso de inscrição formal, a família se inscreve e aguarda que uma criança cadastrada para adoção lhe seja apresentada. Após a apresentação, se ocorrer o acolhimento da criança, durante as primeiras semanas, a família inscrita é acompanhada por um técnico do Setor de Adoção. Depois que os adotantes dão entrada nos Autos de adoção, o Juiz defere a guarda provisória e determina que seja feito um novo estudo psicossocial, no qual se avalia, entre outros aspectos, a adaptação e aceitação da criança pela família, durante o estágio de convivência, que deve preceder à adoção propriamente dita (a sentença e o mandado de cancelamento e confecção de novo registro civil).

Com relação ao estágio de convivência, o Setor de Adoção procura dar um prazo, no mínimo de 60 dias para realizar o estudo. Uma outra atribuição desse setor é o cadastramento das crianças para adoção, a partir de determinação do Juiz da Infância e da Juventude. Em geral, esse cadastramento é precedido da audiência dos genitores na qual concordam com a adoção e abrem mão de seus direitos sobre a criança. Em geral, a oitiva é realizada apenas com a genitora, posto que, na maior parte das vezes, a criança não tem sua paternidade biológica reconhecida. $\mathrm{O}$ cadastramento de criança para adoção também pode ser decorrente de um processo de destituição de pátrio poder. Uma preocupação do Setor de Adoção é a de colocar uma criança cadastrada para adoção em lar substituto no menor tempo possível. Quando se trata de recém-nascidos saudáveis (especialmente do sexo feminino), essa colocação é realizada sem maiores problemas, porém, como já foi apresentado, quando o perfil da criança é diferente da idealização da maioria dos adotantes, esta colocação se torna mais difícil.

A experiência da preparação para adoção envolve diversos elementos que merecem explicitação. Muitos autores (Vargas, 1998; Weber, 1998) apontam para a necessidade de 
preparação dos candidatos à adoção, ao invés de simplesmente avaliá-los e selecioná-los. Nesse Setor de Adoção, a equipe técnica é sensível à importância da preparação e, desde o início do ano de 2000, vem desenvolvendo um projeto com esse objetivo, denominado Pré-natal da Adoção (Setor de Adoção/VIJ-DF, 2000). Ao estudo psicossocial tradicional, foram incorporadas atividades de grupo, em sua maioria de caráter vivencial, dentro de uma perspectiva similar a de Grupos Multifamiliares (Costa, 1998).

As pessoas inscritas para adoção participam desses grupos, nos quais os principais temas relativos à adoção e acolhimento são discutidos e vivenciados: a motivação para adoção; o perfil idealizado da criança; as principais dúvidas, medos, mitos e preconceitos sociais; como lidar e contar sobre a história de origem da criança (temores, dificuldades, alternativas); os segredos (origem e conseqüências); trâmites legais e processuais (prazos, procedimentos, informações); cuidados específicos para recém-nascidos e adoções tardias (manejo); a infertilidade e a conjugalidade (possíveis dificuldades).

Os sujeitos da presente investigação foram duas famílias que já haviam passado pelo processo de estudo psicossocial de inscrição e de adoção no Setor de Adoção, ambas com parecer técnico favorável à adoção. Foram convidadas sete famílias para realização da entrevista de grupo focal, quatro confirmaram presença, porém apenas duas compareceram. Ambas não tinham fílhos biológicos, uma das famílias (Família Santos) era composta por casal e uma filha adotiva de 7 anos, e a outra (Família Silva) por casal e dois filhos adotivos de 11 e 2 anos de idade. Os dois casais encontravam-se na faixa etária de 35 a 45 anos, eram residentes na cidade de Brasília e possuíam renda mensal entre 5 e 6 salários mínimos. Foi realizado um único encontro, em que o casal Silva compareceu sozinho, ao passo que o casal Santos levou a filha adotiva. No entanto, a criança não pode participar da entrevista, pois não estava bem de saúde.

O instrumento adotado na pesquisa foi a entrevista de grupo focal (Fontana \& Frey, 1994) realizada com as duas famílias. Uma das pesquisadoras conduziu a entrevista, e contou ainda com a presença de dois observadores, instruídos para observarem o comportamento não-verbal do grupo durante a realização da mesma. A entrevista de grupo é definida por esses autores como o questionamento sistemático de vários indivíduos simultaneamente. Essencialmente qualitativa, é uma técnica de coleta de dados, que não podem ser investigados através da entrevista individual. Neste tipo de entrevista, o entrevistador deve dirigir a interação e questionar o grupo, contrabalançando o papel diretivo e de moderador (mediador) da interação, permitindo e estimulando todos os entrevistados a participarem.

O método de entrevista de grupo focal parece ser o mais indicado para este tipo de investigação, dada a natureza subjetiva dos dados a serem coletados: valores, atitudes, crenças dos sujeitos, enquanto um grupo com uma vivência e cultura coletiva específicas. Na entrevista de grupo focal, perguntas abertas e fechadas podem estar combinadas no roteiro da entrevista (entrevista semi-estruturada). Nesse caso, foram planejadas quatro perguntas abertas: Como vocês acham que os técnicos do Juizado deveriam avaliar as famílias adotantes? Pensando na experiência vivida durante o estudo psicossocial, como avaliam que a experiência pessoal, em suas famílias de origem e na família atual, foi considerada ou interferiu no processo de adoção? Consideram que a forma como uma família se apresenta ao Juizado para o estudo técnico é relevante e importante no processo de adoção? Se vocês pudessem realizar outra vez o processo de adoção como se apresentariam de novo ao Juizado?

Com relação aos procedimentos de coleta e análise dos dados, é importante destacar que a entrevista de grupo focal foi realizada em apenas um encontro, de aproximadamente uma hora e meia de duração. Foi gravada em fita cassete, e, posteriormente, transcrita na íntegra. A análise dos resultados foi realizada a partir dessa transcrição.

É essencial esclarecer que, na proposta da investigação qualitativa de González-Rey (1999), análise das informações colhidas tem início com o apontamento dos indicadores, termo proposto para designar aqueles "elementos que adquirem significação graças a interpretação do investigador” (p.113), ou seja sua significação não é acessível de forma direta à experiência, nem aparece em sistemas de correlação. O indicador se constrói com base em informação implícita e indireta, não define nenhuma conclusão do investigador em relação com o estudado, mas representa um momento hipotético no processo de produção da informação, que conduzirá ao surgimento de novos indicadores através das novas idéias do investigador associadas com a construção dos indicadores precedentes. $\mathrm{O}$ indicador pode ser definido como um elemento ou conjunto de elementos, ou ainda, pode ser produzido a partir da combinação de informações indiretas e omitidas, chegando-se à construção de grandes áreas de sentido comum, constituindo-se assim em uma análise temática.

\section{Análise dos Resultados}

\section{A avaliação das famílias sobre critérios no processo de adoção}

As famílias parecem ressaltar cinco dimensões importantes que deveriam ser priorizadas no estudo psicossocial:

a) A motivação: A motivação dos adotantes é vista como algo importante a ser considerado pelos técnicos, contudo o diálogo das famílias parece mostrar que podem existir diferentes motivações e não necessariamente, uma é melhor do que a outra. "Eu acho que o primeiro critério é o porquê de você estar querendo adotar uma criança. Qual é a real intenção naquela adoção..." O casal Santos afirmou que queria um filho e demonstrava entender ser esta uma motivação melhor, pois não vitimizava a criança adotada. "A gente não queria adotar uma criança para ajudar uma criança,... tirar do orfanato... a gente queria um filho". O casal Silva contrapôs que outras motivações também poderiam ser adequadas como amar ou ajudar alguém, oferecer uma família a quem não tem. A esposa argumentou ainda que o desejo para ter filhos poderia não ser assim tão adequado, pois poderia ser decorrente de uma pressão social para gerar filhos e garantir a continuidade da família: “... é muito também de posição social. A família quer ser igual ao contexto".

b) As condições materiais e socioeconômicas: Embora em diversas falas tenha sido ressaltada a importância 
de se avaliar as reais condições materiais e financeiras dos casais adotantes para que possam "dar condições à criança", observou-se que ambas as famílias temem a investigação no tocante às condições materiais e socioeconômicas.

O Juizado vai vasculhar sua vida, quer saber quanto você ganha, onde você mora, quer saber de tudo... Mas eu acho certo. A parte financeira, acho muito importante porque infelizmente não é só o amor, você tem que ter uma certa condição para dar para a criança.

Elas parecem acreditar que a questão socioeconômica é muito importante na avaliação técnica, mas também foi ressaltado que esta deve ter um peso secundário em comparação ao peso da dimensão do amor e do vínculo com a criança. "Mas penso que talvez essa criança estivesse em uma situação muito pior. Você às vezes pode melhorar as condições para ela. Se você tiver amor para dar você vai tentar".

c) O amor e o vínculo como aspectos prioritários: A dimensão do amor e do vínculo é enfatizada. O amor por um "filho do coração" até mesmo pode surpreender. " $A$ gente pega um amor assim... Eu nunca pensei que poderia existir... uma filha do coração. É amor mesmo, muito amor, sabe?" A senhora Silva apontou ainda que o amor e o vínculo que se estabelece com a criança deve ser de natureza diferente, deve ser de pai-filho, mãe-filho. A senhora Santos ressaltou que os técnicos devem procurar conhecer as famílias e ver se dentro delas há amor para dar.

Há ainda um outro aspecto que é o medo que ambas as famílias demonstraram sobre o rompimento dos vínculos com a criança, caso a adoção não seja concretizada, e parecem acreditar que este aspecto deve ser considerado nas avaliações psicossociais, acima de quaisquer outras dimensões.

d) A prioridade para os casais sem filhos: Uma proposta que surgiu foi que os casais sem filhos deveriam ter prioridade para adoção. "Isso deveria se levar muito em conta: a necessidade de um casal sem filho, ter que ter um filho". Um dos entrevistados manifestou acreditar que este deveria ser um critério para decisão durante os estudos psicossociais de adoção. Entre duas famílias, nas quais uma com filhos e outra sem, essa última deveria priorizada. "O casal que não tem filho deveria ter uma certa prioridade sobre os outros". As duas famílias entrevistadas não podiam gerar filhos biológicos. Ambas relataram suas experiências de sofrimento e a angústia de não terem filhos, de serem diferentes do contexto numa sociedade que valoriza a continuidade familiar através dos vínculos de sangue.

e) Perfis compatíveis entre crianças e famílias adotantes: A família Santos manifestou acreditar ser fundamental que haja uma compatibilização mútua entre os perfis do adotante e adotando, e que isto poderá trazer menos dificuldades futuras. "Tem que haver esse consenso, essa habilidade do pessoal da adoção de colocar a criança numa família compatível fisicamente com os pais adotivos". Isso viria a proteger tanto a família, como o membro adotivo, de ser alvo de preconceitos. "A própria criança sente isso... aquela reação negativa das pessoas". Além disso, em muitos momentos, o diálogo parecia indicar que a busca de semelhanças físicas é um ponto importante na constituição ou formação do vínculo entre a família adotante e a criança, tanto do ponto de vista do par parental, como da família extensa.

$\mathrm{Na}$ entrevista, foram ressaltadas as semelhanças entre os adotantes e os filhos adotivos. "Porque as pessoas dizem que ele é a cara do pai. Sempre perguntam: e esses olhos? Eu digo que são os olhos do vovô Santos. Por coincidência papai tem os olhos iguaizinhos aos dela”. É muito comum nos estudos psicossociais de adoção, os adotantes ressaltarem (com orgulho) a semelhança dos filhos adotivos consigo e/ou com o cônjuge e/ou com outros membros da família. Identificarem-se, verem-se um no outro, parece consolidar um vínculo de parentalidade que poderia estar ameaçado de não existir em função da não ligação biológica. Por outro lado, como a literatura aponta, o laço biológico por si só não garante que o exercício da maternidade/paternidade irá ocorrer. Schettini (1998a) aponta que a semelhança aparece, também como uma aspiração tanto dos pais quanto dos filhos numa tentativa de reduzir a inexistência dos laços de sangue. A busca pela semelhança é um empreendimento mútuo de pais e filhos adotivos numa tentativa de selar, definitivamente, a ligação parental.

Sabemos que, para algumas famílias, a questão da semelhança física é fundamental para o exercício adequado da parentalidade e para a construção do vínculo e/ou desenvolvimento do sentimento de amor para com a criança. Entretanto, embora considerem importante e fundamental que haja compatibilidade entre os perfis dos adotantes e do adotando, o fato de já ter vivido na primeira adoção todas as fases de desenvolvimento de uma criança (desde os primeiros dias) levou a família Silva a flexibilizar o perfil da criança a ser adotada (com relação à idade e condições de saúde).

\begin{abstract}
Na primeira adoção a gente pegou uma criança com sete dias. Na segunda adoção, a gente pegou uma criança com três meses e com problema cirúrgico que teve de fazer uma cirurgia com um ano. E uma terceira adoção seria uma criança de três anos. Então, são três períodos completamente diferentes de adoção. Então você entra para adotar a criança com outra cabeça, com outras idéia.
\end{abstract}

\section{A importância da verdade}

Na continuidade de um dos diálogos sobre a semelhança física entre adotante e adotado, as famílias apontam para a importância da criança crescer sabendo a verdade, sabendo que foi adotada. "É fundamental que a criança saiba desde pequena, que é uma criança adotada, justamente, para não ter choque". Apesar de ressaltar a importância do tema, as falas indicam que esta não é uma tarefa fácil, percebe-se que há um receio, um temor de que cedo ou tarde algum problema irá acontecer.

Eu soube de uma história de uma moça que depois de 20 anos se revoltou, ficou sabendo e se revoltou contra a família toda. Efoi um drama. Então essas coisas acontecem de verdade. Eé mais fácil você encobrir o problema, mas e lá na frente? 
Durante este diálogo, o esposo ressaltou: "Na adoção quanto mais certinho você fizer menos problemas você vai ter". Esta última fala parece ainda revelar o estigma do adotado e da adoção que de algum modo sempre dá problema. $\mathrm{O}$ diálogo das famílias nos levou a pensar que talvez se revele a verdade mais por medo de que algo saia errado, do que por acreditar ser um direito da criança conhecer sua história de origem. Neste aspecto, é ressaltado também o caráter orientador dos estudos psicossociais, no tocante a revelação da adoção: "por isso que entra o papel da equipe de adoção, acho que eles têm obrigação de tentar evitar o máximo que o casal venha a ter problema no futuro".

As famílias trouxeram exemplos da vida real em que pais adotivos esconderam dos filhos a verdade e isto acarretou prejuízos graves às relações familiares, à confiança entre pais e filhos e a todos os envolvidos. Embora ambas as famílias tenham contado aos filhos que estes eram adotivos, uma fala indica a existência de fantasias parentais relativas aos laços de sangue que poderiam ser mais fortes e ameaçar os pais adotivos de serem trocados pelos pais biológicos: "a gente corre o risco de eles quererem conhecer os pais biológicos". Schettini (1998a) aponta a dificuldade de muitos pais adotivos enfrentarem o problema da revelação da origem, que vai sendo postergado indefinidamente. $\mathrm{O}$ autor alerta que comunicamos não somente através das palavras, mas também através da linguagem corporal e do inconsciente.

\section{Aspectos da dinâmica familiar}

a) Estabilidade conjugal e familiar: As famílias acreditam que a estrutura e dinâmica familiar é levada em consideração nos estudos psicossociais, em especial, a harmonia do relacionamento conjugal. "Acho que levaram em conta o nosso passado e o presente... Principalmente o presente, nossas experiências do dia-a-dia, do casal... a harmonia, o tipo de relacionamento, a opinião do marido..." A senhora Santos mencionou ainda a importância da família de origem como uma base para a formação do casal e de uma nova família. "Porque eu acho que quando você vem de uma família com uma estrutura sólida, uma estrutura bem formada, você já tem uma condição maior de formar a tua família numa base mais sólida". O senhor Silva levantou a hipótese de que a dúvida em relação à estabilidade de seu casamento e o pouco tempo de inscrição no Juizado podem ter sido fatores ou critérios considerados pelos técnicos para a demora na conclusão da adoção.

Porque nesse período (de espera pela conclusão do processo) de um ano eu poderia ter me separado dela... Então (o Juizado) faz um trabalho todinho e de repente o casal se separa. E a criança fica naquela situação, vai para o pai, vai para a mãe, aí volta para o Juizado para ter aquela briga de quem vai ficar com a criança.

O diálogo entre as duas famílias parece ressaltar ainda importância do critério estabilidade familiar para a proteção da criança de um segundo abandono ou de uma situação indefinida em caso de uma separação conjugal.

b) A aceitação da criança pela família nuclear e extensa: Foi apontado por uma das famílias, que a gravidez, em geral, é aceita mais naturalmente pela família extensa, do que uma adoção, possivelmente, porque já se tem um laço de sangue com a criança e rejeitá-la seria negar o próprio sangue. A senhora Silva referindo-se à criança adotada:

é uma pessoa que vai integrar uma família, mas uma família vista como um todo. Como é que vai ser a aceitação não apenas dos pais, mas dos avós, dos tios, dos primos, porque tem que ser levado em conta tudo isso. E as pessoas têm que enfrentar e conviver com aquilo. Então não é gravidez que a mulher vai e a família aceita. Está na família, mas é uma coisa que vem de fora....

Segundo Schettini (1998b), isto seria decorrente de uma aprendizagem cultural que apregoa a obrigatoriedade de amar aquele ser que foi biologicamente gerado ou com quem temos laços de sangue. Por sua vez, uma adoção implica numa possibilidade maior de rejeição, já que o sentimento de amor é decorrente de uma decisão pessoal e, sendo assim, de acordo com esta cultura de laços de sangue não existiria uma garantia de que o mesmo pudesse ocorrer. A aceitação da adoção pela família extensa, o apoio e aconselhamento recebidos foram considerados importantes para ambas as famílias adotantes.

\section{A vivência das famílias durante o processo de adoção}

O critério para convocação para as entrevistas foi, como citado anteriormente, que as famílias já tivessem sido objeto de um estudo psicossocial visando a adoção.

a) Ansiedade e temor $x$ necessidade de segurança: Uma família teve duas experiências diferentes de adoção: na primeira, embora a entrega da criança tenha sido mais rápida do que os adotantes esperassem, o tempo de estudo e conclusão do processo foi longo, durou um ano. "Nós ficamos um ano sem a certidão, sem a garantia de que ele (o filho adotivo) é seu... É uma situação em que a gente, o casal mesmo, dá uma desestruturada". O casal levantou a hipótese de que a longa espera pela concretização do registro, mesmo já estando com a criança, pode ser ainda mais angustiante, em comparação com a espera para acolher uma criança, pois na medida que se relacionavam com a criança, cada vez mais, o vínculo se tornava forte, $\mathrm{e}$ o medo de um possível rompimento, maior. O excesso de preocupação e temor chegou a "dar uma desestruturada no casal". A família chegou a pensar até em fugir com a criança, caso a adoção não fosse concretizada e por algum motivo, pressentissem sinais de que a criança pudesse ser retirada. "Se o Juizado falar a gente pega as coisas, bota a criança no saco e cai fora”. Já na experiência da segunda adoção, este temor e ansiedade foram menos intensos tanto pelo fato de já terem uma história anterior de contato com o Juizado e de estudo psicosocial, assim como pelo fato de sentirem-se mais seguros no exercício da parentalidade adotiva. "É completamente diferente a questão da primeira e da segunda adoção, porque a primeira é aquela expectativa total do primeiro filho. $O$ segundo já vem assim mais tranqüilo".

A experiência da outra família foi diferente. Embora também estivessem apreensivos e ansiosos com relação 
ao processo, especialmente antes de buscarem a Vara da Infância e da Juventude, a vivência do estudo psicossocial trouxe-lhes confiança, tranqüilidade e segurança. As falas indicam que estes adotantes embora também estivessem receosos e ansiosos com relação à possibilidade de retirada da criança, sentiram-se mais seguros fazendo a adoção através do Juizado, e que o temor exacerbado era infundado e decorrente de uma visão estereotipada da Justiça. " $A$ imagem que as pessoas têm do processo todo da adoção é torcida... a adoção através da Vara da Infância é uma coisa muito mais tranqüila, muito mais transparente, uma segurança para você e para a criança”.

b) A demora na conclusão do processo: Durante a entrevista surgiram queixas a respeito do tempo para a conclusão de todo o processo. A demora inclusive é mencionada como um possível motivo para algumas famílias não adotarem. Como a senhora Silva explica: "o processo todo que é infelizmente muito demorado, tem muitas pessoas que evitam porque é um processo demorado". O processo é concluído com o registro da criança no nome dos adotantes. Naturalmente, é um momento de fundamental importância para a família que a partir daquele momento tem certeza que a criança é sua “de papel passado". Assim, o prazo na conclusão do processo é vivido com muita ansiedade, ainda que a adoção tenha ocorrido através da Justiça e esteja com todos os critérios e parâmetros legais.

c) Vasculhamento $X$ exposição $x$ proteção: As famílias parecem viver o estudo psicossocial como um vasculhamento de sua vida. No entanto, perceberam esse vasculhamento como necessário, a fim de minimizar os riscos para todos e, em especial para a criança, de uma adoção mal-sucedida. Contudo, uma fala parece indicar que, ainda que necessário durante o processo de estudo psicossocial, esse "vasculhamento expõe demais" o adotante, possivelmente gerando ansiedade e sofrimento. Em diversos momentos da entrevista, esta dimensão do vasculhamento ou super-exposição foi enfatizada. Os diálogos mostraram que as famílias acreditam ainda que uma pessoa, que queira adotar uma criança, pode tentar disfarçar, mascarar alguma coisa, e que portanto, o estudo deve ser criterioso e as visitas devem ser de surpresa. Uma das mães ponderou que a necessidade de ter um filho, às vezes, é tanta que o adotante pode não medir esforços para conseguir seu intento, mesmo que não reúna condições para isso. Ainda que haja a possibilidade de haver algo encoberto e escondido, ou ainda, mascarado/disfarçado, as famílias parecem acreditar que o estudo psicossocial é capaz de detectar isso e agir em defesa dos interesses da criança.

Pode acontecer da pessoa também fazer pintar um quadro maravilhoso e no dia-a-dia não ser nada daquilo. Mas, cabe aos técnicos do Juizado, pessoas especializadas nessa área, poder avaliar, beliscar, fazer aquelas perguntas maliciosazinhas (sic) que pegam a pessoa desprevenida e ela acaba se entregando.

Nesse sentido, o caráter invasivo do estudo psicossocial parece ser relativizado como necessário e pertinente à proteção do adotando e das próprias famílias.

\section{O papel do acaso e do divino}

No entanto, a adoção também é uma roleta, uma loteria. Para o casal Santos, a chamada para adoção veio antes do que imaginavam. Com pouco tempo de inscrito, foram chamados para acolher uma criança, e segundo eles, a técnica que os convocou disse que "todo mundo estava de férias e havia viajado", desta forma, eles passaram na frente de vários candidatos à adoção. O casal Silva ressaltou a importância do papel de Deus no acerto da adoção: "Por coincidência, papai tem os olhos iguaizinhos aos dela. Quando Deus dá para você ele dá o melhor".

\section{Confiança no estudo psicossocial}

Em resumo, as famílias parecem acreditar e confiar na competência e habilidade do estudo psicossocial para fazer a realização da adoção. É importante apontar que indicaram crença nas boas intenções daqueles que buscam o Juizado, mas também disseram que uma boa avaliação "protege a família que pode estar cega" diante da sua necessidade de ter filhos. "Existe a possibilidade de maquiar, mas existe o trabalho do técnico que vai pegar alguma coisa que está encoberta”. Uma boa avaliação aumenta as chances da adoção ser bem sucedida. A colaboração da família também é enfatizada como um fator importante durante o estudo psicossocial. "Nós estamos agora dispostos a adotar a Fulana... com amor, com transparência... e disposto assim a fornecer toda e qualquer informação que venha favorecer ao quadro técnico uma avaliação perfeita na entrega da criança”.

\section{Considerações Finais}

Especialmente do ponto de vista psicossocial, o contexto judiciário possibilita o acesso de famílias e indivíduos a serviços e profissionais aos quais muitos nunca tiveram acesso. Motta (2001), ao comentar sobre as reações das equipes médicas ao acompanharem as gestantes que pretendem entregar as crianças, nos faz refletir sobre uma "neutralidade profissional" (p.174) e um bom senso, necessários na relação com essas gestantes na hora do parto, no sentido de não influenciá-las para que não entreguem a criança. Do mesmo modo, compreendemos que essa reflexão deve estar presente no estudo psicossocial da adoção, para que sejam preservadas as condições de avaliação da família e os interesses da criança sejam assegurados.

É ainda Motta (2001) que nos chama a atenção sobre a importância dos técnicos do judiciário como peças fundamentais ao longo do processo de colocação de crianças. No caso do contexto judiciário, e em se tratando de um tema tão importante, o bom atendimento deve ser a pedra fundamental em que se alicerça todas as outras. O respeito, o profissionalismo, a educação, a gentileza para com as pessoas que buscam a Instituição dão o tom de qualidade aos serviços prestados. A vivência do estudo psicossocial e o bom atendimento recebido trouxeram-lhes confiança, tranqüilidade e segurança. As falas indicam que embora estivessem receosos e ansiosos com relação à possibilidade de retirada da criança, os adotantes sentiram-se mais seguros fazendo a adoção 
através do Juizado. E que o temor exacerbado era infundado e decorrente de uma visão estereotipada da Justiça.

Por outro lado, não se pode deixar de considerar que o contexto judiciário com sua conotação de lei e obrigatoriedade pode ser um importante catalisador para a mudança, mas também pode ser precursor de arbitrariedades, especialmente em nosso país em que a desigualdade e a falta de cidadania estão muito presentes. Neste sentido, é fundamental a mudança de paradigma, que passa a entender o contexto judiciário como um contexto de possibilidades ao invés de limites, como alerta Sudbrack (1998).

As duas famílias entrevistadas obtiveram êxito em suas petições para adoção. Precisamos ter isso em mente, pois seus depoimentos corroboram a importância da avaliação. Possivelmente, os resultados não seriam os mesmos, caso tivéssemos optado por conversar com famílias cujos pedidos tivessem sido negados. Mesmo assim, muitos aspectos levantados pelas famílias adotantes são importantes e merecem consideração.

No que diz respeito à motivação e condições materiais, parece um tanto óbvio que qualquer processo de avaliação levantaria esses dados, mas a proposta de prioridade de adoção para um casal sem filhos revela que a criança pode ser vista como um "prêmio". Então quem já o possui não necessita de outro.

A importância dada à compatibilidade de perfis entre criança e família, parece-nos uma tentativa de controle e previsão de surpresas, com relação a problemas com a criança, os quais poderão surgir, caso a indicação seja aleatória. Ou seja, quanto mais parecida com os adotantes a criança for, maior é a chance da adoção ser bem sucedida. $\mathrm{Na}$ verdade, isso nos faz pensar no peso que as significações têm nos processos de adoção (Motta, 2001), já que ao se receber uma criança para adotar, parece que se está recebendo também um herdeiro das imaginações contidas dessas famílias. Por outro lado, como Schettini (1998b) alerta, a busca pela semelhança é um empreendimento mútuo de pais e filhos adotivos, inseridos em uma cultura que valoriza os laços de sangue, numa tentativa de selar, definitivamente, a ligação parental e reduzir a inexistência dos laços de sangue. Entretanto, como Vargas (1998) aponta, num trabalho de preparação, com aproximações sucessivas, pode-se chegar a uma adequação da família sonhada com a família possível.

Também Weber (1999) aposta na importância da preparação e acompanhamento dos candidatos à adoção a ser realizado pelos Serviços de Adoção dos Juizados, ao invés de apenas avaliar, selecionar e excluir. De modo semelhante, as famílias entrevistadas valorizam as informações e orientações recebidas durante o estudo psicossocial, ressaltando inclusive a necessidade de maior divulgação do tema na mídia para desmascarar mitos e preconceitos de forma a auxiliar outros adotantes a buscar a realização de uma adoção legal.

E finalmente, parecem-nos pertinentes, as observações acerca dos sentimentos vividos pelos adotantes durante o processo avaliado como demorado, ansiogênico e invasivo. Na perspectiva da avaliação psicossocial, essas queixas precisam ser melhor compreendidas e enfrentadas, pois um processo avaliativo bem realizado envolve essas demandas.
Mas talvez, deva-se atentar mais para o "vasculhamento" apontado pelas famílias, porque vasculhar significa investigar, pesquisar, conhecer detalhadamente as informações fornecidas. Se por um lado, isto é percebido como importante e necessário para o bem estar, a segurança e a proteção do binômio família-criança, por outro lado, esse penetrar nas motivações, sonhos e relações interpessoais dos adotantes pode provocar um sentimento de vulnerabilidade, no qual a pessoa teme ser julgada, atacada e ferida. E é importante destacar que essas famílias apresentam-se, no momento do pedido por uma adoção, preocupadas, com medo, ansiosas e temendo falhar e, portanto, vulneráveis.

\section{Referências}

Badinter, E. (1985). O amor conquistado. (W. Dutra, Trad.) Rio de Janeiro: Nova Fronteira, $5^{\mathrm{a}}$ ed. (Trabalho original publicado em 1980).

Berthoud, C. (1998). A paternidade idealizada e a paternidade possível. Páginas Brasileiras de Adoção. Disponível em 15/12/2002 em http://lexxa.com.br/PBA/index.htm em 15/12/2002.

Brasil. (1990). Estatuto da Criança e do Adolescente. Lei 8.069 de 13.07.90.

Casellato, G. (1998). Motivos relacionados a luto e fracasso que levam uma casal à adoção: uma possibilidade psicoprofilática. Páginas Brasileiras de Adoção. Disponível em 15/12/2002 em http://lexxa.com.br/PBA/index.htm em 15/12/2002.

CODEPLAN (1998). Anuário estatístico do DF. Brasília, DF: Autor.

CODEPLAN (1999). Anuário estatístico do DF. Brasília, DF: Autor.

Costa, L.F. (1998). Reuniões multifamiliares: uma proposta de intervenção em psicologia clínica na comunidade. Tese de Doutorado, Universidade de São Paulo, São Paulo.

Diniz, J. (1991). Adoção: notas para uma visão global. Em F. Freire (Org.), Abandono e adoção: contribuições para uma cultura da adoção (pp. 13-29). Curitiba: Terre des Hommes.

Fontana, A. \& Frey, J. H. (1994). Interviewing: The art of science. Em N. Denzin \& Y. Lincoln (Orgs.), Handbook of qualitative research (pp. 361-376). London: SAGE.

Ghesti, I., Campos, N. \& Silveira, M.C. (2000). Perfil da Adoção no DF. Trabalho apresentado no I Congresso Psicossocial Jurídico do TJDFT, Brasília-DF.

Giberti, E., De Gore, S. \& Taborda, B. (1997). Madres Excluídas. Buenos Aires: Kapelusz.

González-Rey, F. (1999). La investigación cualitativa en psicología: rumbos y desafíos. São Paulo: EDUC.

Hartman, A. (1994). Segredos na adoção. Em E. Imber-Black (Org.). Os segredos na família e na terapia familiar (D. Baptista, Trad.) (pp. 94-112). Porto Alegre: Artes Médicas.

Imber-Black, E. (1994). Os segredos na família e na terapia familiar: uma visão geral. Em E. Imber-Black (Org.), Os segredos na família e na terapia familiar (D. Baptista, Trad.) (pp. 15-39). Porto Alegre: Artes Médicas.

Kvale, S. (1996). Interviews: an introduction to qualitative research interviewing. London: SAGE.

Minayo, M.C. (1998). O desafio do conhecimento: pesquisa qualitativa em saúde. São Paulo: HUCITEC-ABRASCO.

Motta, M.A.P. (2001). Mães abandonadas: a entrega de um filho em adoção. São Paulo: Cortez. 
Nabinger, S. (2000). As origens como herança: o contexto jurídico enquanto cenário de resgate da família de adolescentes adotivos. Trabalho apresentado no II $^{\circ}$ Encontro Científico da Associação Centro Oeste de Terapia Familiar, Brasília, DF.

Schettini, L.F. (1998a). Compreendendo o filho adotivo. Recife: Bagaço.

Schettini, L.F. (1998b). Compreendendo os pais adotivos. Recife: Bagaço.

Sudbrack, M.F. (1998). Abordagem da família no contexto judicial. Manuscrito não publicado, Universidade de Brasília.
Vargas, M.M. (1998). Adoção tardia: da família sonhada à família possível. São Paulo: Casa do Psicólogo.

Venâncio, R.P. (1999). Famílias abandonadas: assistência à criança de camadas populares no Rio de Janeiro e Salvador - séculos XVIII e XIX. Campinas: Papirus.

Weber, L.N.D. (1998). Laços de ternura: pesquisas e histórias de adoção. Curitiba: Santa Mônica.

Weber, L.N.D. (1999). Aspectos psicológicos da adoção. Curitiba: Juruá. 